\title{
THE BENEFITS OF CLIMATE FOR INCLUSION FOR GENDER-DIVERSE GROUPS
}

\author{
LISA H. NISHII \\ Cornell University
}

\begin{abstract}
I introduce the construct of climate for inclusion, which involves eliminating relational sources of bias by ensuring that identity group status is unrelated to access to resources, creating expectations and opportunities for heterogeneous individuals to establish personalized cross-cutting ties, and integrating ideas across boundaries in joint problem solving. I show that within inclusive climates, interpersonal bias is reduced in such a way that gender diversity is associated with lower levels of conflict. In turn, the negative effect that group conflict typically has on unit-level satisfaction disappears. This has important implications, as unit-level satisfaction is negatively associated with turnover in groups.
\end{abstract}

In the last several years, diversity rhetoric has shifted from a focus on diversity management to one on inclusion. The focus on inclusion reflects the recognition that for organizations to reduce problems associated with demographic diversitysuch as high levels of conflict and turnoverorganizations need to proactively create inclusive environments that make it possible to leverage diversity's potential benefits (Holvino, Ferdman, \& Merrill-Sands, 2004). In inclusive environments, individuals of all backgrounds-not just members of historically powerful identity groups-are fairly treated, valued for who they are, and included in core decision making. Like the "multicultural" organizations described by Cox (1993), inclusive environments are characterized by a collective commitment to integrating diverse cultural identities as a source of insight and skill (Ely \& Thomas, 2001). They are distinguished from "plural" organizations that focus on increasing diverse representation but continue to expect nontraditional employees to assimilate to dominant norms (Davidson \& Ferdman, 2001).

I would like to thank this journal's editor, Jason Colquitt, for his invaluable guidance through the review process, as well as the reviewers for their thoughtful feedback. I would also like to thank Benjamin Schneider for instilling in me a deep appreciation for the power of organizational climate. This research was funded by a grant supported by the Office of Disability Employment Policy of the U.S. Department of Labor (E-9-4-6-0107). The opinions contained in this publication are those of the author and do not necessarily reflect those of the U.S. Department of Labor.
The key to moving from a plural organization to an inclusive one is to alter the sociorelational context within which heterogeneous individuals interact. Inclusion is hampered when employees perceive others in terms of oversimplified and negative stereotypes and interpersonal interactions are perverted by status dynamics (DiTomaso, Post, \& Parks-Yancy, 2007). The implementation of diversity practices that are targeted specifically at improving the employment outcomes of historically disadvantaged groups such as women and ethnic minorities may, in and of itself, fail to foster true inclusion for two reasons. First, as Green and Kalev (2008) argued, diversity management practices may help to reduce bias in key personnel decision-making moments, but they are unlikely to alter the day-to-day relational sources of discrimination that impact people's experiences of inclusion. Rather, what is required for enhancing inclusion is more consistent with prescriptions made by Allport (1954) long ago: that people (a) are of approximately equal status; (b) have opportunities to get to know each other in more personal ways, establish cross-cutting ties, and rely less on stereotypes; and (c) work together across roles, levels, and demographic boundaries to solve shared problems through participative decision making (cf. Brewer \& Miller, 1984, 1988; Ensari \& Miller, 2006; Fiol, Pratt, \& O'Connor, 2009). Second, to the extent that diversity management practices that focus specifically on improving the outcomes of historically disadvantaged groups cause resentment or backlash on the part of individuals who do not directly benefit from these practices, they can have the un- 
intended effect of exacerbating negative stereotypes and perceived intergroup competition (Fiol et al., 2009).

The current wisdom is that to really manage both the problems and the potential benefits associated with diversity, organizations need to create environments that are inclusive of all employees (Ferdman \& Davidson, 2004; Shore, Randel, Chung, Dean, Ehrhart, \& Singh, 2011). Despite the growing awareness of the potential benefits associated with cultivating inclusive environments, empirical testament of the power of inclusion is scarce. Thus, the goal of this research is to introduce the construct of climate for inclusion, and to examine its benefits for group processes and outcomes in gender-diverse groups. Although diversity research has focused on the effects of demographic diversity on a wide variety of group process variables (e.g., communication, cohesion, cooperation, social integration), I chose to focus on group conflict, since almost every review of the group diversity literature has suggested that a primary explanation for the frequent association of demographic diversity with negative group outcomes is that heterogeneous groups tend to experience higher levels of conflict (e.g., DiTomaso et al., 2007; Jackson, Joshi, \& Erhardt, 2003; Herring, 2009; King, Hebl, \& Beal, 2009; Mannix \& Neale, 2005; Milliken \& Martins, 1996; van Knippenberg, De Dreu, \& Homan, 2004; van Knippenberg \& Schippers, 2007; Williams \& O'Reilly, 1998). In describing the relationship between demographic diversity and group conflict, management researchers have borrowed almost exclusively from psychological theories of social identity and social categorization, in which it is assumed that categorizations of others based on demographic attributes result almost automatically in biases that favor in-group members over outgroup members (Bargh \& Chartrand, 1999).

A different view emerges from sociological approaches to workforce diversity. In particular, proponents of status characteristics theory (Ridgeway, 1991; Ridgeway \& Correll, 2006) argue that social identity differences among group members are psychologically meaningful only when they are correlated with status rankings and access to resources in ways that reinforce historical and societal trends (DiTomaso et al., 2007; Ridgeway, 1991). When structural and status relationships within an organization legitimize sociohistorical status beliefs, they perpetuate stereotyping and bias related to cultural identity. Thus, the psychological meaningfulness of a cultural identity refers to more than perceptual salience or cognitive accessibility (Oakes, Haslam, \& Turner, 1994; Pearsall, Ellis, \& Evans, 2008). To the extent that organizational factors such as climate for inclusion invalidate arbitrary status hierarchies in a local context, a particular identity characteristic can lose its psychological meaning so that it no longer triggers the negative social categorization processes that result in conflict.

Building upon this notion, I examine how climate for inclusion affects the relationships between gender diversity and group conflict and between conflict and group members' aggregate satisfaction, with the expectation that group-level satisfaction in turn predicts unit turnover. Although theoretically I expect climate for inclusion to influence dynamics associated with all forms of demographic diversity, I focus specifically on gender diversity in this study for a number of reasons. First, for an initial test of climate for inclusion's beneficial effects, my preference was to focus on a dimension of diversity that represents a universally relevant problem (Kabeer, 2003; Mor-Barak, 2005; Sen, 2001; Shen, Chanda, D’Netto, \& Monga, 2009). In addition, the "fixedness" of gender-based status differentials is dramatic (Sidanius \& Pratto, 1999), and therefore there is a significant need to continue to explore the conditions under which the negative interpersonal dynamics associated with gender-based status differentials can be mitigated. Moreover, gender is a particularly important type of diversity for conflict, since its visibility makes it a highly likely trigger of conflict (Pelled, 1996). My decision to focus primarily on gender diversity in this study was further reinforced by the nature of the organization that populated my sample, in which gender disparities tend to be more serious than disparities based on any other identity characteristics; as a result, gender differences tend to be particularly salient and psychologically meaningful in this context.

This study is intended to extend research in four key ways. First, it provides a much needed empirical operationalization of inclusive climates. Second, it responds to calls for research on the moderators of the link between diversity and group processes such as conflict (King et al., 2009; van Knippenberg et al., 2004; van Knippenberg \& Schippers, 2007) and does so utilizing field data. Third, in doing so, it extends existing research on group conflict by being among the first studies to (a) examine the moderating role of social context as created by an organization (i.e., unit climate) rather than task or group structure characteristics (e.g., Jehn, Northcraft, \& Neale, 1999; Pearsall et al., 
2008; Pelled, Eisenhardt, \& Xin, 1999; Webber \& Donahue, 2001) or personal preferences (e.g., Ayoko \& Härtel, 2003; Mohammed \& Angell, 2004) and (b) improve understanding of the factors that can mitigate the negative effects of relationship conflict. Finally, this study contributes to research on the business case for diversity by linking group diversity and conflict with turnover. Lower turnover associated with diversity continues to be one of the greatest challenges faced by organizations (McKay, Avery, Tonidandel, Morris, Hernandez, \& Hebl, 2007).

\section{HYPOTHESES}

\section{Climate for Inclusion}

In their seminal work, Ely and Thomas (2001) used qualitative methods to arrive at a rich description of the different approaches to managing diversity adopted by organizations. They described the most inclusive organizations as adopting a "learning and integration" perspective that is characterized by the belief that people's diverse backgrounds are a source of insight that should be utilized to adapt and improve the organizations' strategic tasks. To successfully resource diversity for learning, employees are expected to expend considerable effort exploring their differences and exhibit a deep commitment to educating each other so that they can infuse their thinking with greater cultural competence. Although scholars have since added to conceptual understanding of inclusion (e.g., Holvino et al., 2004; Shore et al., 2011), there are no published quantitative studies of inclusive climates. Thus, I begin with a brief description of the three dimensions that constitute climate for inclusion.

As in past work emphasizing the importance of unbiased organizational practices and targeted diversity practices for establishing a positive climate for diversity (e.g., Hicks-Clarke \& Iles, 2000; McKay et al., 2007; Mor Barak, Cherin, \& Berkman, 1998), the first dimension involves a foundation of fairly implemented employment practices and diversityspecific practices that help to eliminate bias. ${ }^{1}$ Percep-

\footnotetext{
${ }^{1}$ Compared to prior conceptualizations of justice climate (e.g., Colquitt et al., 2002), this dimension of climate for inclusion is broader in its focus, as it taps not just the fairness with which HR practices in general are implemented, but also how well diversity-specific practices such as grievance procedures are implemented. Fur-
}

tions of justice signify a "level playing field" (Colquitt, Noe, \& Jackson, 2002); biased employment practices, however, perpetuate demographically based status differentials in organizations (Greenhaus, Parasuraman, \& Wormley, 1990). When employees perceive the distribution of resources to correlate with identity group membership, members of the group(s) perceived as favored tend to be considered a normative in-group and to command more respect, deference, and power (Ridgeway, Boyle, Kuipers, \& Robinson, 1998). This makes individuals' membership in the normative in-group versus out-group salient and informative for interpersonal dynamics.

Although this dimension is similar to some prior conceptualizations of diversity climate that also focus on the fairness of organizational practices (e.g., Gilbert \& Ones, 1999; Hegarty \& Dalton, 1995; Hicks-Clarke \& Iles, 2000; Kossek \& Zonia, 1993; Mor Barak et al., 1998), the construct of climate for inclusion is broader in scope, as the next two dimensions illustrate. As mentioned previously, creating inclusive climates requires more than increasing diverse representation and implementing equitable human resources (HR) practices; it requires a change in interaction patterns. In recognition of this, the second dimension, integration of differences, captures the interpersonal integration of diverse employees at work. It reflects collective expectations and norms regarding the openness with which employees can enact and engage core aspects of their self-concept and/or multiple identities (Kahn, 1990; Ramarajan, 2009) without suffering unwanted consequences (Ragins, 2008). ${ }^{2}$ This dimension reflects elements of Berry's (1984) model of acculturation in that it contrasts integrationist environments in which all individuals retain substantial pieces of their own cultural identities with assimilationist environments in which nondominant groups conform to the values and norms of a dominant group. In integrationist environments, group members are able to develop more

thermore, the climate for inclusion construct is comprised of two additional dimensions that focus on social and decision-making integration, both of which are clearly distinct from justice climate.

${ }^{2}$ Like the construct of climate for psychological safety (Edmondson, 1999), this dimension has to do in part with felt psychological safety, though the focus here is more on the safety that employees feel about engaging their personal identity, beyond the safety that they may feel about taking risks related to their group's task. 
complex perceptions of others, thereby perceiving greater variability among members of other identity groups (Brewer \& Miller, 1984, 1988; Ensari \& Miller, 2006). Personalized contact of this sort has been shown to disconfirm negative stereotypes of out-group members and diminish the in-group/outgroup distinctions that fuel conflict (Ensari \& Miller, 2001, 2002, 2005). In contrast, work on facades of conformity (Hewlin, 2003, 2009) and surface acting (Hochschild, 1983) suggests that when people constrain their emotions and behaviors in order to construct public representations of themselves that are aligned with desired organizational personas, they suffer from strain and psychologically disengage from their work (Clair, Beatty, \& MacLean, 2005).

Finally, the third dimension, inclusion in decision making, captures the extent to which the diverse perspectives of employees are actively sought and integrated, even if expressed ideas might upset the status quo (Ely \& Thomas, 2001; Mor Barak \& Cherin, 1998). In inclusive climates, the questioning of dominant assumptions is not seen as a threat, but rather as a value-enhancing proposition, and thus barriers that could perpetuate organizational silence (Morrison \& Milliken, 2000) are actively eliminated. In such contexts, group members will have more opportunities to engage in interactions that enable them to contribute to "double-looped learning” (Argyris \& Schön, 1978) and develop a more differentiated and personalized understanding of the unique characteristics of out-group members (Ensari \& Miller, 2006). Indeed, such democratic decision-making processes have been hailed by some as critical for the reduction of stereotypes and bias (e.g., Green \& Kalev, 2008).

\section{Climate for Inclusion as a Moderator of the Link between Gender Diversity and Conflict}

The primary explanation for diversity's association with group conflict is that visible differences like gender lead to categorization processes that trigger intergroup biases, as reflected in inflated levels of conflict (Pelled, 1996; Tajfel \& Turner, 1986). When others' perspectives are perceived through a social categorization lens, they tend to be viewed negatively and therefore lead to derogation and conflict (Larkey, 1996). Although metaanalytic results involving the relationship between gender diversity and group conflict are not available, inflated levels of conflict likely account for the negative relationship found in a meta-analysis of the relationship between gender diversity and team performance (Bell, Villado, Lukasik, Belau, \& Briggs, 2011). To attenuate this effect, a contextual moderator would have to reduce the propensity for gender-based categorization processes to lead to intergroup bias. There are two theoretical reasons to expect that a unit's climate for inclusion would have this desired effect.

First, according to research on expectation states (Berger, Fiske, Norman, \& Zelditch, 1997) and structural ritualization theories (Knottnerus, 1997), in an organizational context in which organizational resources are evenly distributed across men and women, gender-based (arbitrary) social hierarchies become invalidated (Jasso, 2001; Ridgeway \& Correll, 2006). When gender (or any other cultural identity) is no longer predictive of favored status, intergroup animosity and biases based on gender will be much less likely to be exhibited (cf. Brewer, 1999; Hogg \& Terry, 2000). In less inclusive climates, however, men are likely to hold a disproportionately large amount of "social value" as members of the favored social category, thereby contributing to the perception that material and symbolic resources (e.g., "voice," in the sense of opportunity to speak, and inclusion) are scarce, which in turn breeds competition and negative affect (Brewer, 1999). In addition, because lower-status women are expected to assimilate into the dominant culture as defined by favored male employees (Eagly, Wood, \& Diekman, 2000), the threat to them of having their behavior evaluated in terms of deviance from dominant norms exacerbates intergroup biases and conflict.

In indirect support of these arguments, Wagner, Ford, and Ford (1986) showed that the effect of gender-based status inequalities on interpersonal interactions can be reduced by disconfirming gender-based status expectations. Wagner et al.'s (1986) work, along with that of Epstein (1979), suggests that in contexts in which the correlation between gender and favored status is eliminated, status-neutral men will be less likely to dominate interactions and expect assimilative behaviors on the part of women, and instead will be more likely to share voice and treat women with respect. As a result, affective conflict should be lower in genderdiverse groups with inclusive climates. In a similar line of work, Jasso (2001) showed how genderbased status hierarchies are completely dependent on the distribution of "first-order" status characteristics between men and women. To the extent that men and women have similar amounts of charac- 
teristics that are valued in a particular context (e.g., access to resources, opportunities, and voice), status hierarchies can be eliminated in that context. However, when the social system in a context assigns higher status to one sex, it creates incentives for members of the social system to defend status in terms of sex, often in the form of mistreatment and harassment based on sex (cf. Berdahl, 2007), as evidenced in higher levels of group conflict.

The second reason to expect that climate for inclusion will attenuate any positive relationship between gender diversity and group conflict is related to the value that is placed on self-expression as a means of engaging in "deep learning" (Ely \& Thomas, 2001), which helps employees in inclusive climates to feel psychologically safe to be authentic. By sharing their personal identities and perspectives, they are more likely to foster interpersonal trust (Ensari \& Miller, 2006) and experience self-verification, or be seen by coworkers as they seem to themselves (Polzer, Milton, \& Swann, 2002). As a result, feelings of connectedness among group members should increase, thereby facilitating better communication and interpersonal harmony rather than conflict (Jackson et al., 2003). As relational ties that cut across genders are cultivated, people begin to categorize each other in more complex and personalized ways (Lau \& Murnighan, 1998; Mannix \& Neale, 2005), thereby making it more likely that they become able to accept one another's differences (Larkey, 1996) and personally committed to maintaining meaningful interdependencies that are not so governed by identity differences (Brickson \& Brewer, 2001).

Indeed, recent research by Ramarajan (2009) showed that individuals who are able to engage multiple identities at work are more open to different perspectives and able to integrate multiple viewpoints successfully, indicating that they should be better able to exchange perspectives productively. Furthermore when people reveal, rather than suppress, aspects of their identity that are important to them, coworkers will be better able to see them as they are (Polzer et al., 2002); this enables group members to engage in healthy task-related debate without misinterpreting one another or labeling task-related exchanges as conflict per se. As a result, gender diversity should be associated with lower levels of relationship and task conflict than would be the case in work contexts that perpetuate categorization-based perceptual processes and behaviors. Accordingly:
Hypothesis 1. A unit's climate for inclusion moderates the relationship between gender diversity and relationship conflict: lower levels of relationship conflict are experienced in genderdiverse groups that enjoy highly inclusive climates than in diverse groups with climates that are not as inclusive.

Hypothesis 2. A unit's climate for inclusion moderates the relationship between gender diversity and task conflict: lower levels of task conflict are experienced in gender-diverse groups that enjoy highly inclusive climates than in gender-diverse groups with climates that are not as inclusive.

\section{Climate for Inclusion as a Moderator of the Link between Conflict and Satisfaction}

In all types of diverse groups, relationship conflict has been shown to be negatively associated with unit-level satisfaction (i.e., group member satisfaction aggregated to the unit level), and positively associated with unit-level turnover (De Dreu \& Weingart, 2003). Surprisingly, scholars have found that norms for openness about conflict and collaboration fail to attenuate the negative outcomes of relationship conflict. Norms for openness had the unintended effect of leading people to experience more intense and vicious relationship conflicts that are less likely to be resolved in satisfactory ways (Jehn, 1995). Similar results were found in response to norms for collaboration (De Dreu \& Van Vianen, 2001); the only strategy that worked for preserving team functioning and effectiveness was for people to ignore conflict altogether. While it is understandably tempting to ignore conflict, it is far from ideal to do so, for it means that conflicts go unresolved and are allowed to fester, making it impossible for group members to improve rapport and understanding (Fiol et al., 2009). Promoting norms for collaboration and/or openness may be ineffective because they focus only on conflict itself, and not also on the more general interpersonal context within which the conflicting parties are embedded.

Work by Brewer (1999) suggests that highlighting the need for cooperation can backfire when the parties involved differ in social status, since pressure to cooperate makes the absence of mutual trust salient. Without mutual trust that comes from the elimination of arbitrary status differences and the development of cross-cutting ties, individuals in 
noninclusive climates are likely to fear that attempts to be cooperative may be exploited, leading them to scapegoat and blame rather than cooperate. This leaves little chance for relationship conflicts to be resolved effectively. In comparison, individuals in inclusive climates are more likely to show concern both for themselves and for the other parties involved in the conflicts (Rahim \& Bonoma, 1979). Furthermore, in inclusive climates, conflicts are more likely to be viewed as an important source of interpersonal insight-an opportunity for individuals to deepen their understanding of cultural differences in the service of collective goals. In support of this, Ely and Thomas reported that participants working in "integration and learning" contexts describe the value of "learning how not to be afraid of the differences, learning about conflict, and learning to be willing to go toward it and trying to talk about hard things" (2001: 242). Thus, in contrast to meta-analytic findings that relationship conflict is negatively associated with satisfaction, I hypothesize:

Hypothesis 3. The negative relationship between relationship conflict and satisfaction is attenuated or reversed in units with highly inclusive climates.

Mirroring relationship conflict, task conflict is negatively associated with team member satisfaction, despite past theorizing to the contrary (De Dreu \& Weingart, 2003). A number of contextual moderators are known to attenuate this relationship: norms promoting openness (Jehn, 1995), cooperative goal interdependence (Alper, Tjosvold, \& Law, 2000), openness to diverse viewpoints (Amason, 1996; De Dreu \& West, 2001; Simons \& Peterson, 2000), and/or the use of collaborative communication when expressing disagreements (Lovelace, Shapiro, \& Weingart, 2001). Each of these is more likely in inclusive climates, thereby leading to the following:

Hypothesis 4. The negative relationship between task conflict and satisfaction is attenuated or reversed in highly inclusive climates.

\section{Unit Satisfaction and Turnover}

The nature of the link between satisfaction and turnover is intuitive: since satisfaction is a reflection of the extent to which individuals' needs are satisfied through their jobs, those who are satisfied are more motivated to go to work, where their needs are satisfied (Lawler \& Porter, 1967). On the other hand, dissatisfaction with work or with negative interactions with coworkers represents a system "shock" that inspires turnover (Lee \& Mitchell, 1994). Turnover influences the bottom-line outcomes associated with diversity, as it relates negatively with operational efficiency (Alexander, Bloom, \& Nuchols, 1994), wage costs (Balkin \& Gomez-Mejia, 1984), revenue growth (Baron, Hanna, \& Burton, 2001), sales (Kacmar, Andrews, Van Rooy, Steilberg, \& Cerrone, 2006), and productivity (Huselid, 1995). Since unit-level financial data are not available for all types of work groups, turnover remains one of the few outcome variables that are relevant in all organizational units. Thus, I propose:

Hypothesis 5. Unit-level satisfaction is negatively associated with unit-level turnover.

\section{METHOD}

\section{Sample}

The organization that participated in this research was a large biomedical company. Interviews with representatives of the company revealed that gender disparities are more serious than disparities based on any other identity characteristic, a finding that echoes concerns expressed by the National Institutes for Health about the sciences in general, and about the biomedical field in particular (Pollner, 2008). In this organization, gender disparities are driven primarily by educational differences between men and women, as pay grades and status are highly dependent on whether an employee has a doctoral degree. Data provided by the organization indicated that women are more likely to have lower-level degrees than men. However, data about the relative status of ethnic minorities revealed that they were proportionately less likely to have lowerlevel degrees and more likely to have medical and doctoral degrees. Thus, according to the principles of status expectations theory (Ridgeway, 1991), it would be reasonable to expect that in this organization, ethnicity-based stereotypes may be debunked. Accordingly, I expected that there would be less room for climate for inclusion to improve group outcomes associated with racial diversity and focused on gender diversity in the test of study hypotheses, although I also present results involving other forms of diversity.

In total, data from 1,324 employees working in 100 departments of a regional site of the company were collected. Of them, 57 percent were female 
and 43 percent were male. In terms of ethnicity, 81 percent were white; 4 percent, black; 3.5 percent, Hispanic; 0.7 percent, Native American; 9 percent, Asian; 0.8 percent, multiracial; and the remainder, "other." As for unit tenure, 16 percent had been working in their units for less than 1 year; 52.8 percent, for $1-5$ years; 20.8 percent, for $6-10$ years; 8.7 percent, for 11-20 years; and 1.5 percent, for more than 20 years. Average age was 40.90 years. The average group (unit) size was 13.24 individuals, with a standard deviation of 8.86. The average within-unit response rate was 72 percent.

\section{Measures}

Climate for inclusion: Scale development. The three dimensions of climate for inclusion were assessed with items that were generated deductively (Hinkin, 1998) from a review of existing literature on diversity climate (Gilbert \& Ivancevich, 2000; Hegarty \& Dalton, 1995; Hicks-Clarke \& Iles, 2000; Kossek \& Zonia, 1993; McKay et al., 2007; Mor Barak et al., 1998) as well as emerging conceptualizations of inclusion (Bormann \& Woods, 1999; Ely \& Thomas, 2001; Holvino et al., 2004; Roberson, 2006). This process revealed that, compared to diversity climate, which tends to focus on the fairness of personnel practices and the treatment of minority employees, inclusion focuses more broadly on the engagement of whole selves and learning from divergent perspectives. The advantage of deductive scale development is that it helps to ensure content validity, because the items are written to reflect an existing construct definition; however, as an added check of content validity, I asked a group of ten practitioners and scholars to assess the content validity of the items by matching them to the corresponding definitions of the three dimensions. Only items that at least 90 percent of the coders classified correctly were retained. These 47 scale items (rated on a five-point scale), together with other measures to assess criterion validity, were administered to 633 university employees, representing a more than adequate item-to-response ratio (Schwab, 1980). An exploratory factor analysis on the items suggested that, after items with low $(<.40)$ and double factor loadings had been dropped, a final set of 31 items loaded on three factors with eigenvalues greater than one. Together, these factors accounted for 64.85 percent of the variance.

The scale was cross-validated on a sample of 701 working adults who provided criterion data three weeks after the administration of the scale. Confirmatory factor analysis (CFA) on the 31 items showed that the three-factor structure-consisting of fairness of employment practices, integration of differences, and inclusion in decision makingexhibited excellent fit $\left(\chi_{421}^{2}=865.43\right.$, CFI $=.98$, RMSEA $=.04$, SRMR $=.03)$. Each dimension exhibited high reliability ( $\alpha=.93, .94$, and .97) and acceptable aggregation statistic values (Bliese, 2000), suggesting that climate for inclusion emerges as a shared unit-level construct. For all three dimensions, the ICC1 value was .05; ICC2 values were .71, .64, and .71 ; and $r_{\mathrm{wg}}$ values were .93, .94, and .97, respectively. Factor loadings for the 31 items are shown in Table 1. Criterion-related validity was established in both two samples: Climate for inclusion was significantly related to attitudinal (e.g., satisfaction, commitment, perceived organizational support) and behavioral (e.g., citizenship behaviors, turnover intentions [intentions to quit]) variables, in keeping with expectations. ${ }^{3}$

In addition, these analyses revealed that the three dimensions of climate for inclusion are moderately related to, but distinct from, procedural and interactional justice (correlations range from .50 to .59, $p<.01$; assessed using 15 items from Niehoff and Moorman [1993]). To further test the distinctiveness of the climate for inclusion scale from procedural and interactional justice, I also ran a CFA involving the 15 items of climate for inclusion that were utilized to test study hypotheses (see below), and the procedural and interactional justice items. Results indicated that model fit was best when climate for inclusion, procedural justice, and interactional justice were three separate factors $\left(\chi^{2}{ }_{983}=\right.$ $3,473.61$, CFI $=.94$, RMSEA $=.06$, SRMR $=.03$ ). This model fit significantly better $\left(\Delta \chi^{2}{ }_{7}=\right.$ 11,227.19) than a single-factor model $\left(\chi^{2}{ }_{98}=\right.$ $14,700.79$, CFI $=.64$, RMSEA $=.13$, SRMR $=.12$ ) and also significantly better $\left(\Delta \chi^{2}{ }_{2}=438.27\right)$ than a model with two factors, one representing climate for inclusion and another representing overall justice $\left(\chi_{985}^{2}=3,911.88\right.$, CFI $=.92$, RMSEA $=.06$, SRMR = .04).

Climate for inclusion: The current study. Some estimates place the cost of turnover to be as high as

\footnotetext{
${ }^{3}$ A presentation of results to demonstrate criterionrelated validity of the climate for inclusion measure is beyond the scope of the current study, but more detailed information about these relationships can be requested from the author.
} 
TABLE 1

Confirmatory Factor Analysis Factor Loadings ${ }^{a}$

\begin{tabular}{ccc}
\hline & Equitable & Inclusion in \\
Employment & Integration of & Decision \\
Practices & Differences & Making
\end{tabular}

Dimension 1: Foundation of equitable employment practices

1. This [unit] is committed to having diverse employees well-distributed throughout the organization.

2. The employment/HR practices of this [unit] are fairly implemented. $\quad .70$

3. This [unit] has a fair promotion process.

$\begin{array}{ll}\text { 4. The performance review process is fair in this [unit]. } & .71\end{array}$

5. In this [unit], the unique needs of employees are met by flexible benefit programs. $\quad .63$

6. This [unit] invests in the development of all of its employees.

7. Employees in this [unit] receive "equal pay for equal work."

8. This [unit] provides safe ways for employees to voice their grievances. $\quad .78$

9. People in this [unit] can count on receiving a fair performance review.

Dimension 2: Integration of differences

1. In this [unit], employees are comfortable being themselves.

2. This [unit] is characterized by a non-threatening environment in which people $\quad .74$ can reveal their "true" selves.

3. Promoting diversity awareness is a priority of this [unit]. 63

$\begin{array}{ll}\text { 4. This [unit] values work-life balance. } & \mathbf{7 6}\end{array}$

5. In this [unit], people's differences are respected.

6. Employees in this organization are actively encouraged to take advantage of 66 work-life balance programs.

7. This [unit] commits resources to ensuring that employees are able to resolve $\quad .76$ conflicts effectively.

8. Employees of this [unit] are valued for who they are as people, not just for the .84 jobs that they fill.

9. In this [unit], people often share and learn about one another as people.

10. This [unit] has a culture in which employees appreciate the differences that people bring to the workplace.

11. Intergroup relations (i.e., between different races, workgroups, age groups, etc.) tend to be characterized by respect and trust within this [unit].

Dimension 3: Inclusion in decision making

1. In this [unit], employee input is actively sought.

2. It is clear that this [unit] perceives employee input as a key to its success.

3. Employees in this [unit] are empowered to make work-related decisions on their own.

4. In this [unit], people's ideas are judged based on their quality, and not based on who expresses them.

5. This [unit] has a climate for healthy debate.

6. In this [unit], everyone's ideas for how to do things better are given serious consideration.

7. Employees in this [unit] are encouraged to offer ideas on how to improve operations outside of their own areas.

8. In this [unit], employees' insights are used to rethink or redefine work practices.

9. Top management exercises the belief that problem-solving is improved when input from different roles, ranks, and functions is considered.

10. Employees in this [unit] engage in productive debates in an effort to improve decision making.

11. This is an [unit] in which employees make use of their own knowledge to enhance their work.

${ }^{\text {a }}$ Bolded items were included in the shortened, 15-item version of the scale.

200-250 percent of annual pay (U.S. Department of Labor Center for Faith-Based Community Initiatives, 2008), which is a sizable amount for any organization, but particularly for organizations with highly skilled employees, as was the case with the organization participating in this research. Therefore, limiting the length of the survey was necessary. A shortened, 15-item version of the scale 
was used. Indicated by the bolded items in Table 1, these items were selected on the basis of factor loadings, content, and wording. Shortening the scale did not noticeably reduce the coefficient alphas for any of the subdimensions. Next, I conducted CFA analyses on the data from the 1,324 respondents in this study using the "COMPLEX" analysis method in Mplus, which takes into account the nonindependence of individual observations within departments. Results indicated that a model in which the items loaded onto their three theoretical factors exhibited excellent fit $\left(\chi^{2}{ }_{80}=\right.$ $217.97, \mathrm{CFI}=.98$, RMSEA $=.04$, SRMR $=.02)$. The scaling correction factor for MLR, or the chi-square to degrees of freedom ratio that is corrected for clustered data (Satorra, 2000), was 1.23. Additional CFA analyses suggested that the three dimensions load on to a second-order factor. Because it is not possible for a "just-identified" higher-order solution to improve goodness of fit over a first-order model, a second-order solution that does not result in a significant decrease in goodness of fit can be interpreted as accounting for correlations among the first-order factors (Brown, 2006). In the current analysis, the first- and second-order models exhibited identical values for chi-square, degrees of freedom, and fit. The standardized second-order factor scores for the climate for inclusion dimensions were .86, .92, and .88, respectively, and the correlations among dimensions ranged from .76 to 83 . The standardized residuals suggest that a high proportion of the variance in the first-order dimensions is explained by the second-order factor: 74 , 85, and 78 percent, respectively. Therefore, all subsequent analyses were conducted using a total climate for inclusion score based on the average of the three dimensions $(\alpha=.93)$. The mean $r_{\mathrm{wg}}$ value across units was .94. The ICC1 value was .13, and the ICC2 was .64 (Bliese, 2000).

Gender diversity. Gender diversity was calculated using Blau's (1977) index, which is the most commonly used index of diversity for categorical variables. The most recent meta-analysis involving the relationship between gender diversity and team performance revealed that of the 26 field studies published, 23 of them conceptualized gender diversity as variety using Blau's index (Bell et al., 2011). The formula used to calculate this index is $1-\Sigma p_{k}{ }^{2}$, where $p$ is the proportion of unit members in the $k$ th category. Blau values, which range from 0 to 1 , capture the spread of group members over qualitatively different demographic categories, with maximum values being reached when group members are spread equally over possible categories of a demographic variable. Implicit in the use of Blau's index is the assumption that the effects of gender diversity on conflict are symmetric (Harrison \& Klein, 2007); that is, a group comprised of 30 percent women should not be qualitatively different from a group comprised of 70 percent women. In units lacking inclusive climates, arbitrary status hierarchies are legitimized in such a way that gender separates individuals who are more favored, included, and powerful (i.e., men) from those who are not (i.e., women), thereby triggering conflict, regardless of whether women are in the minority or majority. For these reasons, Blau's index was deemed to be appropriate.

Group conflict. To allow comparisons to be made between this study and the accumulated research evidence involving group conflict, I measured both relationship and task conflict using three items developed by Jehn rated on a five-point scale (Jehn \& Mannix, 2001). An example relationship conflict item is, "How often do people get angry while working in your work unit?" An example task conflict item is, "How much conflict of ideas is there in your work unit?" For relationship conflict, mean $r_{\mathrm{wg}}$ was .77, ICC1 was .13, and ICC2 was .67; for task conflict, the mean $r_{\mathrm{wg}}$ value was .79 , the ICC1 was .14, and the ICC2 was .69.

Unit satisfaction. In response to the partner organization's interest in utilizing a measure of satisfaction that would enable benchmarking against national norms, satisfaction was assessed with the item "How satisfied are you in your job?" from the 2006 General Social Survey (http://gss.norc.org/). Scale options range from 1, "completely dissatisfied," to 7, "completely satisfied." The estimated reliability for single-item measures of satisfaction is close to .70 (Wanous, Reichers, \& Hudy, 1997). Because individual-level responses were aggregated to the unit level following the additive model of composition, according to which the unit-level mean is of interest regardless of the variance within units, empirical justification for aggregation using ICC values is considered unnecessary (Chan, 1998). Nevertheless, some variability between units was expected (Ostroff, 1992) and was confirmed ( $F=$ 1.37, $p<.01)$.

Turnover. Actual turnover was measured instead of turnover intentions, since the latter are only predictive of actual turnover under some conditions (Vandenberg \& Nelson, 1999), as evidenced by an only moderately strong $(r=.45)$ correlation (Griffeth, Hom, \& Gaertner, 2000). As in past re- 
TABLE 2

Means, Standard Deviations, and Correlations ${ }^{a}$

\begin{tabular}{|c|c|c|c|c|c|c|c|c|}
\hline Variable & Mean & s.d. & 1 & 2 & 3 & 4 & 5 & \\
\hline 1. Gender diversity & 0.37 & 0.15 & & & & & & \\
\hline 2. Climate for inclusion & 3.21 & 0.35 & $.21^{*}$ & & & & & \\
\hline 3. Relationship conflict & 2.38 & 0.49 & $-.21^{*}$ & $-.64^{*}$ & & & & \\
\hline 4. Task conflict & 2.41 & 0.42 & -.13 & $-.58 * *$ & $.79 * *$ & & & \\
\hline 5. Unit-level satisfaction & 4.82 & 0.51 & $.20 *$ & $.51^{*}$ & $-.40 * *$ & $-.37^{* *}$ & & \\
\hline 6. Unit-level turnover & 0.05 & 0.05 & $-.52 * *$ & $-.23^{*}$ & $.28 * *$ & $.26 * *$ & $-.33 * *$ & \\
\hline 7. Justice climate & 3.60 & 0.28 & $.39 * *$ & $.68 * *$ & $-.51 * *$ & $-.47^{* *}$ & $.52 * *$ & $-.35 * *$ \\
\hline
\end{tabular}

${ }^{\text {a }} n=100$ units. Higher diversity indexes correspond to higher heterogeneity.

${ }^{*} p \leq .05$

${ }^{* *} p \leq .01$

search (e.g., George \& Bettenhausen, 1990), approximately six months after survey administration, the organization provided information on the number of people who had voluntarily left the organization each month. I divided this number by the total number of employees who were in a unit at the time of survey data collection to arrive at a turnover rate for each unit (Hausknecht, Trevor, \& Howard, 2009).

\section{Analyses}

Following recent recommendations related to testing moderated mediation models (e.g., Edwards \& Lambert, 2007; Preacher, Rucker, \& Hayes, 2007), I tested all hypotheses simultaneously in a structural equation model (SEM) using bootstrapping, controlling for other forms of group diversity that have been shown to relate to group conflict: racial diversity (calculated using the Blau index), age diversity (calculated using the standard deviation of unit members' age), educational diversity (conceptualized in terms of diversity as disparity, calculated as the coefficient of variation using data about the level of education attained by each team member), and tenure diversity (calculated using standard deviation). ${ }^{4}$ In addition, because research has

\footnotetext{
4 Theoretically, I expected the effects of gender diversity to be symmetric in this study, thereby justifying the use of Blau's index. Analyses suggested this was the case, as the percentage of females in a group was not negatively associated with study variables, as one might expect if one assumed that subgroup dynamics would be worse in minority female as compared to majority female groups. Nevertheless, I also tested study hypotheses with percentage of females in a unit as the operationalization of gender diversity. The interaction between percentage
}

indicated that group size can influence group dynamics (Brewer \& Kramer, 1986; Wegge, Roth, Neubach, Schmidt, \& Kanfer, 2008), I also controlled for group size in the analyses.

Finally, because the first dimension of climate for inclusion, fairness of employment practices, is conceptually related to justice climate, I also controlled for distributive justice climate using six items, four from Niehoff and Moorman's (1993) scale and two added to broaden the range of distributive outcomes assessed. Example items are, "I feel that my job responsibilities are fair" and "Overall the opportunities for training that I receive are fair." The reliability of the scale was .82. Coefficients relating to all control variables appear in Table 3, together with the rest of the SEM results.

\section{RESULTS}

\section{Test of Study Hypotheses}

Descriptive statistics for and correlations among unit-level variables are shown in Table 2, and the standardized path coefficients from the SEM analyses are shown in Table $3\left(\chi_{2}^{2}=20.20\right.$; CFI $\left.=.99\right) .^{5}$ Analyses revealed that none of the control variables were significantly associated with the study variables. Hypothesis 1 was supported in that climate for inclusion had a significant moderating effect on

of females and climate for inclusion was not predictive of either form of group conflict.

${ }^{5}$ In light of past work suggesting that the effects of surface-level diversity retreat over time as group members get to know each other (e.g., Harrision, Price, \& Bell, 1998), I reran the analyses while controlling for average unit tenure. Doing so did not affect the pattern of results. 
TABLE 3

SEM Results for Testing All Hypotheses Simultaneously ${ }^{a}$

\begin{tabular}{|c|c|c|c|c|c|c|c|c|}
\hline \multirow[b]{2}{*}{ Variables } & \multicolumn{2}{|c|}{$\begin{array}{l}\text { Relationship } \\
\text { Conflict }\end{array}$} & \multicolumn{2}{|c|}{ Task Conflict } & \multicolumn{2}{|c|}{$\begin{array}{c}\text { Unit } \\
\text { Satisfaction }\end{array}$} & \multicolumn{2}{|c|}{ Turnover } \\
\hline & $\boldsymbol{\beta}$ & s.e. & $\boldsymbol{\beta}$ & s.e. & $\boldsymbol{\beta}$ & s.e. & $\boldsymbol{\beta}$ & s.e. \\
\hline \multicolumn{9}{|l|}{ Control } \\
\hline Department size & .03 & .00 & -.03 & .00 & -.03 & .00 & -.22 & .00 \\
\hline Tenure diversity & .11 & .14 & .14 & .12 & -.06 & .15 & -.03 & .00 \\
\hline Education disparity & .12 & .68 & .13 & .65 & -.20 & .86 & -.01 & .00 \\
\hline Justice climate & -.11 & .21 & -.10 & .18 & .25 & .18 & -.18 & -.02 \\
\hline \multicolumn{9}{|l|}{ Predictor } \\
\hline Gender diversity & -.10 & .30 & .03 & .26 & .10 & .34 & -.17 & -.05 \\
\hline Climate for inclusion & $-.56^{* *}$ & .17 & $-.51 * *$ & .14 & $.41 * *$ & .21 & .23 & .03 \\
\hline Gender diversity $\times$ climate for inclusion & $-.22^{* *}$ & .80 & $-.23 * *$ & .72 & $.21^{*}$ & .94 & .03 & .03 \\
\hline Satisfaction & & & \multirow{2}{*}{\multicolumn{2}{|c|}{.50}} & & & $-.32^{*}$ & -.03 \\
\hline$R^{2}$ & \multicolumn{2}{|c|}{.45} & & & \multicolumn{2}{|c|}{.43} & \multicolumn{2}{|c|}{.37} \\
\hline
\end{tabular}

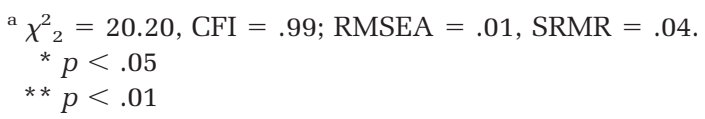

the relationship between gender diversity and relationship conflict $(\beta=-0.22, p<.01$ ). The nature of this interaction is graphically represented in Figure 2. An analysis of the simple slopes show that in units with low climate for inclusion, gender diversity is associated with higher relationship conflict $(b=1.61, p<.01)$, while in units with high levels of climate for inclusion, gender diversity is negatively associated with relationship conflict $(b=-2.18, p<.01)$. Hypothesis 2 was similarly supported in that climate for inclusion significantly moderates the relationship between gender diversity and task conflict $(\beta=-0.23, p<$ .01). Simple slope analyses revealed a similar pattern to that found for relationship conflict. It is important to note the direct relationships between climate for inclusion and both relationship $(\beta=-0.56, p<.01)$ and task $(\beta=-0.51, p<.01)$ conflict are negative, regardless of levels of gender diversity.

Hypothesis 3 was also supported, as the interaction of climate for inclusion and relationship conflict in predicting unit satisfaction was significant ( $\beta=0.45, p<.01)$. As illustrated in Figure 3 , in units with a low climate for inclusion, relationship conflict is negatively associated with satisfaction ( $\beta=-0.27, p=.05)$, which is consistent with meta-analytic results (De Dreu \& Weingart, 2003). However, in units characterized by a high climate for inclusion, the negative relationship becomes

FIGURE 1

\section{Study Hypotheses}

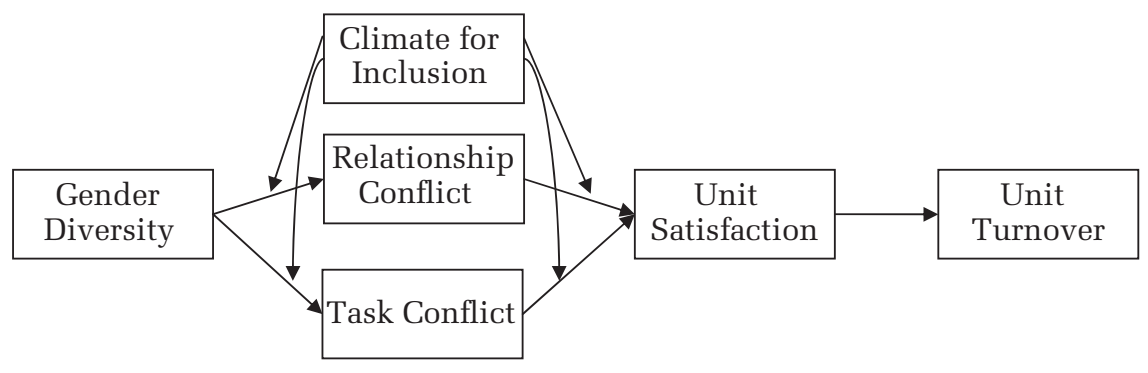


FIGURE 2

Interaction of Climate for Inclusion and Gender Diversity in Predicting Relationship Conflict

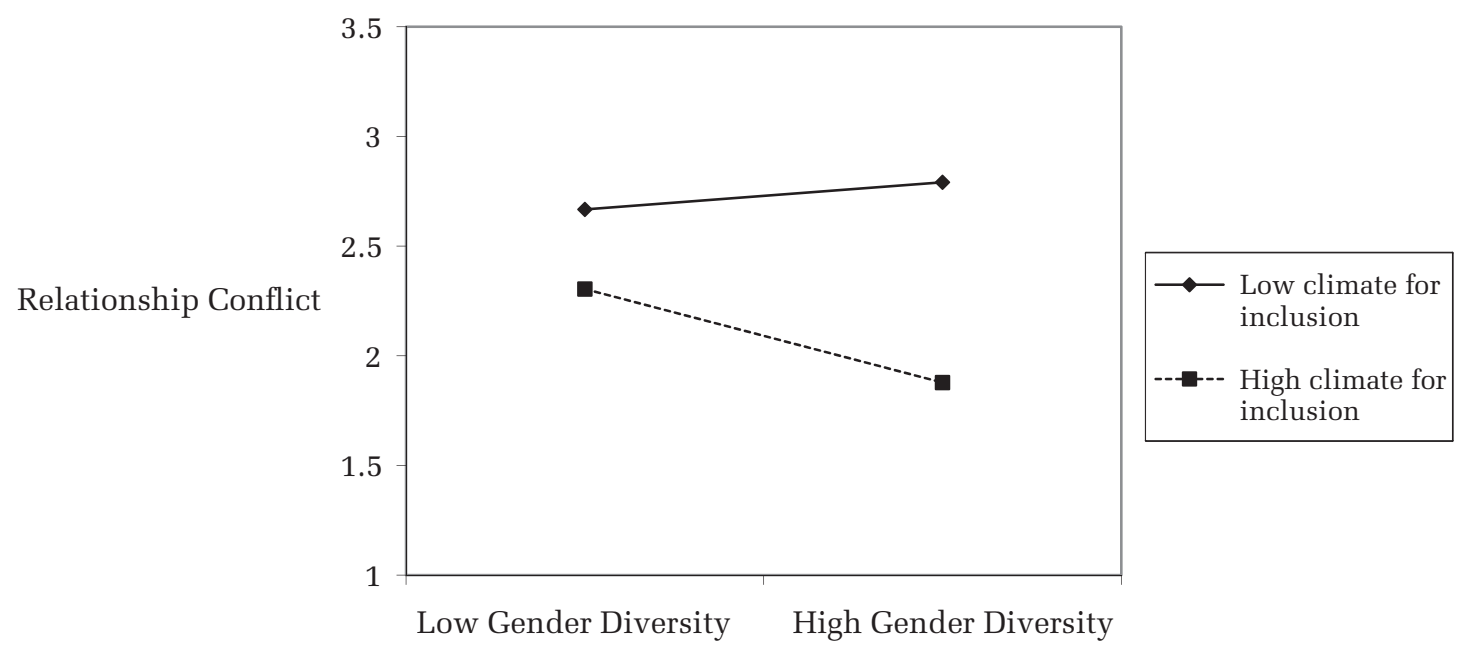

nonsignificant $(\beta=0.04, p>.10)$. The direct relationship between task conflict and unit satisfaction was not significant $(\beta=0.05, p>.10)$, nor was the one moderated by climate for inclusion $(\beta=-0.31$, $p>$.10). Thus, Hypothesis 4 was not supported. In support of Hypothesis 5, net of the other predictors, unit satisfaction was negatively associated with turnover $(\beta=-0.32, p<.05)$. In keeping with recent prescriptions (Edwards \& Lambert, 2007; Preacher et al., 2007), I examined the product of the coefficients representing the first and second stages of the moderated mediation to determine whether the conditional indirect effects were significant. In keeping with the pattern of results described above, the conditional indirect effect of gender diversity on unit satisfaction through relationship conflict (i.e., moderated by climate for inclusion) was significant ( $\beta=-2.55, p<.05)$, but the indirect effect through task conflict was not significant ( $\beta=1.34$, $p>.10)$.

Finally, as mentioned previously, gender diversity was deemed to be more salient than racioethnic diversity within the organization partnering in this research. However, to confirm this assumption, I tested the hypotheses using racial diversity while controlling for the main and in-

FIGURE 3

Interaction of Climate for Inclusion and Relationship Conflict in Predicting Unit Satisfaction

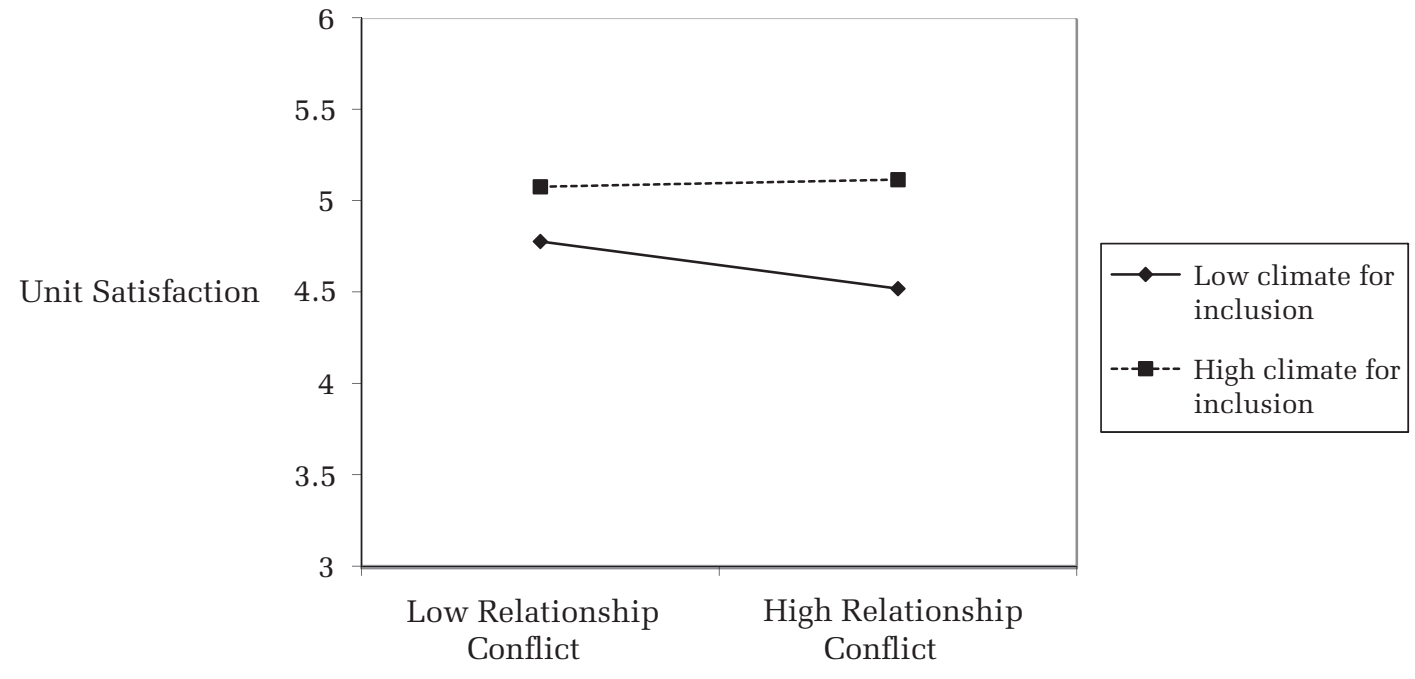


teractive (gender diversity $\times$ climate for inclusion) effects of gender diversity. I also ran the same analyses involving age diversity, tenure diversity, and educational diversity (as disparity) and found that none of these forms of diversity were significantly associated with study variables, nor were any of the relationships significantly moderated by climate for inclusion, although climate for inclusion itself was a significant predictor of relationship and task conflict as well as unit-level satisfaction in all cases.

\section{DISCUSSION}

Using data collected from employees in 100 units of an organization, three of the four hypothesized interactions involving climate for inclusion were supported. In keeping with expectations, both relationship and task conflict were significantly lower in gender-diverse groups with high climate for inclusion than in diverse groups with low climate for inclusion. Perhaps even more remarkable is that the negative association between relationship conflict and satisfaction disappears when climate for inclusion is high. This finding lies in stark contrast with the negative correlation between relationship conflict and unit satisfaction found in all 14 studies reviewed in the meta-analysis by De Dreu and Weingart (2003) and in contrast with the outcomes of other studies that have searched in vain for moderators that might attenuate or eradicate the negative consequences of relationship conflict (e.g., De Dreu \& Van Vianen, 2001; Jehn, 1995; Jehn et al., 1999). There are a number of theoretical and practical implications of these findings.

\section{Theoretical Implications}

These results represent an important theoretical contribution because they illustrate that social context plays a key role in influencing whether group diversity leads to conflict, as proposed by social categorization and identity theories (Tajfel \& Turner, 1986; Williams \& O’Reilly, 1998). Whether gender diversity triggers the social identity processes that lead to conflict depends not only on whether it is perceptually salient (Randel, 2002), but also on whether gender is a meaningful predictor of social status in a given social context (Hogg \& Terry, 2000; Sidanius \& Pratto, 1999). In inclusive climates, fairly implemented employment practices that do not bias against women, a lack of stigmas associated with expressing feminine iden- tity, and a propensity to value the perspectives of men and women equally signal to employees that being a woman is not associated with having a disproportionately small share of social value. In contrast, when gender-based status differences are salient, people will be motivated to derogate others on the basis of gender in order to enhance their own status (Berdahl, 2007). Members of the higherstatus group are likely to be perceived with envy, and members of lower-status groups are likely to be perceived with contempt (Caprariello, Cuddy, \& Fiske, 2009), both of which perpetuate mistrust and conflict (Brewer, 1999). Although gender identity appeared to be the only psychologically meaningful driver of interpersonal interactions in this organization, it is important to keep in mind that cultural identities are socially constructed (Ely, 1995; Ely \& Thomas, 2001). Structural and power relationships in an organization define whether a particular cultural identity makes a difference and are key to understanding how identity groups interact and, ultimately, to whether there is any reason to expect identity differences to trigger negative group processes (Brickson \& Brewer, 2001; DiTomaso, Post, \& Parks-Yancy, 2007; Mannix \& Neale, 2005; Ridgeway \& Correll, 2006). Future research situated in an organization in which racial and other demographic disparities are salient needs to be conducted to extend the results of the current study and also to disentangle the direct and moderating effects of climate for inclusion on group processes and outcomes.

Another key finding of this study was that inclusive climates attenuate the negative association between relationship conflict and group satisfaction. Typically, relationship conflicts cause people to feel personally attacked and defensive, causing dissatisfaction among organization members who feel uncomfortable working among hostile coworkers (Jehn, 1994; Jehn, Chadwick, \& Thatcher, 1997). In inclusive climates, however, relationship conflict does not appear to damage unit morale; in fact, the interaction plotted in Figure 3 shows a slight positive relationship between relationship conflict and unit satisfaction in inclusive climates, though this slope was not significant. It may be that the relationship conflicts that do arise are interpreted not as personal attacks, but as valued signals that group members may not understand each other as well as they had thought. Given that expressions of interpersonal difference are considered critical for the development of collective cultural competence and improved work processes in inclusive climates, group members who become involved in relation- 
ship conflicts may be more willing to spend the time and energy necessary to ensure that learning, rather than antagonism, results from the conflicts. Ultimately, if coworkers are able to successfully resolve and learn from relationship conflicts, unit morale is likely to be preserved.

Of course, the mechanisms just described are speculative. Research that thoroughly explicates the processes through which inclusive climates have their effect on the resolution of conflicts is needed. Future research should examine whether the nature of the conflicts experienced in inclusive climates differ qualitatively from those dominating groups with noninclusive climates, or whether both types of groups experience similar conflict episodes but apply different cognitive construals in responding to the conflicts. Conflict construals, or frames, act like schemata in that they help to impart meaning to a conflict episode by guiding people's attention to and interpretation of information (Pinkley, 1990). Past research has shown that individuals from different cultures utilize emic, or culture-specific, conflict construals and also differ in their use of etic, or universal, conflict construals (Gelfand, Nishii, Holcombe, Dyer, Ohbuchi, \& Fukuno, 2001). Building on this work, I expect that on the etic compromise versus win dimension, conflicts may be viewed more in terms of compromise in inclusive climates but as win/competition in noninclusive climates. On the etic intellectual versus emotional dimension, conflicts may be more emotionally charged in noninclusive climates because of a lack of trust, but may remain largely intellectual in inclusive climates. There may also be qualitative differences in the construals that are utilized; for example, conflicts in inclusive climates may be interpreted with reference to their implication for mutual learning and identity sharing, while conflicts in less inclusive climates may be seen through the lens of self-protection (e.g., of rights and territory) and discrimination. Future research is needed to identify which of these differences account for the elimination of the negative relationship between relationship conflict and satisfaction in inclusive climates.

The results are also suggestive of the possibility that the negative relationship between relationship conflict and satisfaction was eliminated in inclusive climates because people adopted more "integrating" conflict resolution styles, which enable disputants to arrive at better solutions because they are characterized by a dual concern for self and other (Rahim \& Bonoma, 1979). The expectation is that because status consciousness and competition for material and symbolic resources are lower in inclusive climates, people should be more likely to demonstrate concern for both themselves and others (Rahim \& Bonoma, 1979). In contrast, in less inclusive climates, people may be more likely to exhibit high concern for self but low concern for demographically different others and therefore adopt either a "competing" or "dominating" style. Future research that examines whether individuals adopt conflict resolution styles that match the inclusiveness of a climate would be valuable. Such research should consider the possibility that the conflict styles that are adopted reinforce a unit's climate in a recursive fashion.

An important aspect of inclusive climates is that they facilitate the engagement of whole selves. The expression of multiple identities (Rothbard \& Ramarajan, 2009) in turn increases the probability that cross-cutting ties emerge within groups. Although my assumption has been that inclusive climates facilitate the personalized expression of identities, future research is necessary to empirically test whether the development of cross-cutting ties in inclusive climates reduces people's dependency on any one in-group for meeting their psychological needs for inclusion (Brewer, 1999) and therefore decreases group polarization and conflict. Research should also examine whether employees in inclusive climates develop "concentric loyalties" to their multiple identities and to the inclusive collective that makes this possible, as Allport (1954) suggested could happen under the right conditions. If this were found to be the case, it would contrast with the theoretical assumption that identification with one social identity reduces identification with another (Brickson, 2000).

Finally, the results of the current study provide compelling initial evidence about the beneficial effects of inclusive climates. Interestingly, within a single organization, the inclusiveness of unit climates varied significantly. By extension, this suggests that unit-level managers may play an important role (cf. Mayer, Nishii, Schneider, \& Goldstein, 2007) in delegitimizing status expectations in that their implementation of practices, the norms that they set, and opportunities that they provide for heterogeneous employees can have a substantial effect on within-group dynamics. It would be enormously useful if future research investigated the organizational and individual-level factors that make unit leaders more likely to create inclusive climates. In addition, future research should exam- 
ine the moderating effect that climate for inclusion has on the relationship between group diversity and performance. Given meta-analytic evidence for the negative relationship between conflict and performance (De Dreu \& Weingart, 2003), it is reasonable to expect that diverse groups with inclusive climates may benefit not only from lower levels of conflict but also from better performance. It would also be valuable for future research to assess group process variables other than conflict that may play an important mediating role in the relationship between diversity and performance (e.g., information elaboration; van Knippenberg et al., 2004).

\section{Practical Implications}

The finding that climate for inclusion plays an important role in reducing levels of conflict in diverse groups should be of great interest to organizations, given recent reports from the U.S. Equal Employment Opportunity Commision (2012) that discrimination and harassment charges are on the rise for every single social category that is protected under federal law. This alarming report suggests that organizations continue to struggle to create work environments in which interpersonal interactions are positive and unbiased. Although climate for inclusion was examined as a global construct in this study, it may be useful for managers to think of the first dimension, fairness of employment practices, as being particularly important. I have argued throughout this article that the elimination of arbitrary status hierarchies, or the "disproportionate allocation of positive and negative social value across the social status hierarchy" (Sidanius \& Pratto, 1999: 41) through the fair treatment of employees is a foundational requirement, as it eliminates the context-dependent social stigmas that lead people to hide aspects of their identity and thinking (Hewlin, 2003). Recent work by Leonardelli and Toh (2011) provides some support for this idea; they found that when employees perceive that members of different groups are treated fairly by authorities from a procedural justice perspective, those employees are more likely to engage in positive interactions across group memberships. Thus, an effective place to start in improving an organization's climate for inclusion would be to carefully monitor HR outcomes and employee perceptions of the fairness of employment practices to reveal biases that may stand in the way of making meaningful improvements to the other two dimensions.

The results of this study also contribute to the discourse on the business case for diversity (Cox,
1993) by showing that the negative group outcomes that typically get in the way of realizing the value in diversity hypothesis can be avoided in inclusive climates, and that the economic savings of doing so are likely to be substantial. According to the U.S. Department of Labor (2008), the costs of turnover are estimated to be as high as 200-250 percent of annual pay, which is a sizable amount for any organization, but particularly for organizations with highly skilled employees, as was the case with the organization participating in this research. These estimates do not account for losses in core strategic knowledge, which can be debilitating in knowledge-intensive units like the research and development groups represented in the current sample. Besides the cost savings associated with lower levels of turnover, organizations that successfully reduce levels of relationship conflict should enjoy higher performance (De Dreu \& Weingart, 2003) and fewer legal problems associated with claims of harassment and/or more generalized interpersonal mistreatment (Pearson, Andersson, \& Porath, 2000).

\section{Limitations}

The results of this study should be interpreted within the context of the study's limitations. First, although the inflation of results based on the use of data collected from a single source is not considered to be a problem when interactions are examined (MacKinnon, Lockwood, Hoffman, West, \& Sheets, 2002), all the data except for objective turnover data were cross-sectional. In addition, due to space limitations, an abbreviated version of the climate for inclusion scale was used in this research. Although it exhibited a nearly identical pattern of relationships with other constructs as the full version when examined in the pilot studies, researchers might consider using the full scale in future research in order to maximize construct coverage. Also, because of space limitations existing diversity climate measures could not be included in the current study, and thus future research is needed to explicitly compare the climate for inclusion scale I developed for this research with diversity climate scales to clarify the ways in which climate for inclusion may be a broader construct that explains unique variance. Assuming that existing diversity climate scales (e.g., Mor Barak et al., 1998) overlap most with the fairness of employment practices dimension of the climate for inclusion scale, I ran supplemental analyses that provided at least preliminary evidence that climate for inclusion may be a broader construct, for the second-order cli- 
mate for inclusion scale accounted for more variance than the fairness of employment practices dimension alone. Another limitation is that even though analyses suggested that climate for inclusion significantly moderates the hypothesized relationships when distributive justice climate does not, and hypotheses were supported after distributive justice climate had been controlled for, only distributive justice climate was included in this study. It would have been preferable if I had been able to also include procedural and interactional justice climate measures to further clarify the distinction between climates for inclusion and justice. In addition, the mechanisms through which climate for inclusion is expected to have had its effect need to be verified in future studies. Finally, given the assumption that group diversity measures should accurately reflect the level of diversity in a group, the fact that not all unit members provided survey data means that missing data could be problematic (Allen, Stanley, Williams, \& Ross, 2007).

\section{Conclusion}

As companies increasingly depend on innovation to foster long-term growth and success, it is critical that the downside of diversity be addressed. What is required are solutions that can make productive debate possible while also enhancing cooperation and learning. An important starting point may be to minimize divisive conflict and to do so by minimizing structural inequalities, norms for assimilation, and exclusionary decision-making processes. This study provides at least preliminary evidence that inclusive climates are beneficial in this regard.

\section{REFERENCES}

Alexander, J. A., Bloom, J. R., \& Nuchols, B. A. 1994. Nursing turnover and hospital efficiency: An organization-level analysis. Industrial Relations, 33: 505520.

Allen, N. J., Stanley, D. J., Williams, H. M., \& Ross, S. J. 2007. Assessing the impact of nonresponse on work group diversity effects. Organizational Research Methods, 10: 262-286.

Allport, G. W. 1954. The nature of prejudice. Reading, MA: Addison-Wesley.

Alper, S., Tjosvold, D., \& Law, K. S. 2000. Conflict management, efficacy, and performance in organizational teams. Personnel Psychology, 53: 625-642.

Amason, A. 1996. Distinguishing the effects of functional and dysfunctional conflict on strategic decision making: Resolving a paradox for top management teams. Academy of Management Journal, 39: 123148.

Argyris, C., \& Schön, D. 1978. Organizational learning: A theory of action perspective. Reading, MA: Addison Wesley.

Ayoko, O. B., \& Härtel, C. E. J. 2003. The role of space as both a conflict trigger and a conflict control mechanism in culturally heterogeneous workgroups. Applied Psychology, 52: 383-412.

Balkin, D. B., \& Gomez-Mejia, L. R. 1984. Determinants of $\mathrm{R} \& \mathrm{D}$ compensation strategies in the high tech industry. Personnel Psychology, 37: 635-650.

Bargh, J. A., \& Chartrand, T. L. 1999. The unbearable automaticity of being. American Psychologist, 54: 462-479.

Baron, J. N., Hanna, M. T., \& Burton, M. D. 2001. Labor pains: Change in organizational models and employee turnover in young, high-tech firms. American Journal of Sociology, 106: 960-1012.

Bell, S. T., Villado, A. J., Lukasik, M. A., Belau, L., \& Briggs, A. L. 2011. Getting specific about demographic diversity variable and team performance relationships: A meta-analysis. Journal of Management, 37: 709-743.

Berdahl, J. 2007. Harassment based on sex: Protecting social status in the context of gender hierarchy. Academy of Management Review, 32: 641-658.

Berger, J. M., Fiske, H., Norman, R. Z., \& Zelditch, M. 1997. Status characteristics and social interaction. New York: Elsevier.

Berry, J. W. 1984. Cultural relations in plural societies: Alternatives to segregation and their socio-psychological implications. In N. Miller \& M. Brewer (Eds.), Groups in contact: 11-29. New York: Academic.

Blau, P. M. 1977. Inequality and heterogeneity. New York: Free Press.

Bliese, P. D. 2000. Within-group agreement, non-independence, and reliability: Implications for data aggregation and analysis. In K. J. Klein \& S. W. J. Kozlowski (Eds.), Multilevel theory, research, and methods in organizations: Foundations, extensions, and new directions: 349-381. San Francisco: Jossey-Bass.

Bormann, T., \& Woods, S. 1999. A framework for building organizational inclusion. A Report from the 1998 Alice and Richard Netter Labor-Management Public Interest Seminar, Cornell University, Ithaca, NY.

Brewer, M. B. 1999. The psychology of prejudice: Ingroup love or outgroup hate? Journal of Social Issues, 55: 429-444.

Brewer, M. B., \& Kramer, R. M. 1986. Choice behavior in 
social dilemmas: Effects of social identity, group size, and decision framing. Journal of Personality and Social Psychology, 50: 543-549.

Brewer, M. B., \& Miller, N. 1984. Beyond the contact hypothesis: Theoretical perspectives on desegregation. In N. Miller \& M. B. Brewer (Eds.), Group in contact: The psychology of desegregation: 281302. Orlando, FL: Academic Press.

Brewer, M. B., \& Miller, N. 1988. Contact and cooperation: When do they work? In P. Katz \& D. Taylor (Eds.), Eliminating racism: Means and controversies: 315-326. New York: Plenum.

Brickson, S. 2000. The impact of identity orientation on individual and organizational outcomes in demographically diverse settings. Academy of Management Review, 25: 82-101.

Brickson, S., \& Brewer, M. B. 2001. Identity orientation and intergroup relations in organizations. In M. A. Hogg \& D. J. Terry (Eds.), Social identity processes in organizational contexts: 49-65. Philadelphia: Psychological Press.

Brown, T. A. 2006. Confirmatory factor analysis for applied research. New York: Guilford.

Caprariello, P., Cuddy, A., \& Fiske, S. 2009. Social structure shapes cultural stereotypes and emotions: A causal test of the stereotype content model. Group Processes and Intergroup Relations, 12: 147-155.

Chan, D. 1998. Functional relations among constructs in the same content domain at different levels of analysis: A typology of composition models. Journal of Applied Psychology, 83: 234-246.

Clair, J. A., Beatty, J., \& MacLean, T. 2005. Out of sight but not out of mind: Managing invisible social identities in the workplace. Academy of Management Review, 30: 78-95.

Colquitt, J. A., Noe, R. A., \& Jackson, C. L. 2002. Justice in teams: Antecedents and consequences of procedural justice climate. Personnel Psychology, 55: 83-109.

Cox, T. H. 1993. Cultural diversity in organizations: Theory, research, and practice. San Francisco: Barrett-Koehler.

Davidson, M. N., \& Ferdman, B. M. 2001. A matter of difference-Diversity and inclusion: What difference does it make? Industrial-Organizational Psychologist, 39: 36-38.

De Dreu, C. K. W., \& Van Vianen, A. E. M. 2001. Managing relationship conflict and the effectiveness of organizational teams. Journal of Organizational Behavior, 22: 309-328.

De Dreu, C. K. W., \& Weingart, L. R. 2003. Task versus relationship conflict, team performance, and team member satisfaction: A meta-analysis. Journal of Applied Psychology, 88: 741-749.
De Dreu, C. K. W., \& West, M. A. 2001. Minority dissent and team innovation: The importance of participation in decision making. Journal of Applied Psychology, 86: 1191-1201.

DiTomaso, N., Post, C., \& Parks-Yancy, R. 2007. Workforce diversity and inequality: Power, status, and numbers. In D. S. Massey \& K. S. Cook (Eds.), Annual review of sociology, vol. 33: 473-501. Palo Alto, CA: Annual Reviews.

Eagly, A. H., Wood, W., \& Diekman, A. B. 2000. Social role theory of sex differences and similarities: A current appraisal. In T. Eckes \& H. M. Trautner (Eds.), The developmental social psychology of gender: 123-175. New York: Psychology Press.

Edmondson, A. 1999. Psychological safety and learning behavior in work teams. Administrative Science Quarterly, 44: 350.

Edwards, J. R., \& Lambert, L. S. 2007. Methods for integrating moderation and mediation: A general analytical framework using moderated path analysis. Psychological Methods, 12: 1-22.

Ely, R. J. 1995. The power of demography: Women's social constructions of gender identity at work. Academy of Management Journal, 38: 589-634.

Ely, R. J., \& Thomas, D. A. 2001. Cultural diversity at work: The effects of diversity perspectives on work group processes and outcomes. Administrative Science Quarterly, 46: 229-273.

Ensari, N., \& Miller, N. 2001. Decategorization and the reduction of bias in the crossed categorization paradigm. European Journal of Social Psychology, 31: 193-216.

Ensari, N., \& Miller, N. 2002. The out-group must not be so bad after all: The effects of disclosure, typicality, and salience on intergroup bias. Journal of Personality and Social Psychology, 83: 313-329.

Ensari, N., \& Miller, N. 2005. Prejudice and intergroup attributions: The role of personalization and performance feedback. Group Processes \& Intergroup Relations, 8: 391-410.

Ensari, N., \& Miller, N. 2006. The application of the personalization model in diversity management. Group Processes and Intergroup Relations, 9: 589607.

Epstein, C. F. 1970. Woman's place: Options and limits in professional careers. Berkeley: University of California Press.

Ferdman, B. M., \& Davidson, M. N. 2004. A matter of difference-Some learning about inclusion: Continuing the dialogue. Industrial-Organizational Psychologist, 41(4): 31-37.

Fiol, C. M., Pratt, M. G., \& O’Connor, E. J. 2009. Managing 
intractable identity conflicts. Academy of Management Review, 34: 32-55.

Gelfand, M. J., Nishii, L. H., Holcombe, K. M., Dyer, N., Ohbuchi, K. I., \& Fukuno, M. 2001. Cultural influences on cognitive representations of conflict: Interpretations of conflict episodes in the United States and Japan. Journal of Applied Psychology, 86: 1059-1074.

George, J. M., \& Bettenhausen, K. 1990. Understanding prosocial behavior, sales performance, and turnover: A group-level analysis in a service context. Journal of Applied Psychology, 75: 698-709.

Gilbert, J. A., \& Ivancevich, J. M. 2000. Valuing diversity: A tale of two organizations. Academy of Management Executive, 14(1): 93-105.

Gilbert, J., \& Ones, D. 1999. Development of the diversity practices survey. Psychological Reports, 85: 101103.

Green, T. K., \& Kalev, A. 2008. Discrimination-reducing measures at the relational level. Hastings Law Journal, 59: 1435-1461.

Greenhaus, J. H., Parasuraman, S., \& Wormley, W. 1990. Effects of race on organizational experiences, job performance evaluations, and career outcomes. Academy of Management Journal, 22: 64-86.

Griffeth, R. W., Hom, P. W., \& Gaertner, S. 2000. A metaanalysis of antecedents and correlates of employee turnover: Update, moderator tests, and research implications for the next millennium. Journal of Management, 26: 463-488.

Harrision, D. A., Price, K. H., \& Bell, M. P. 1998. Beyond relational demography: Time and the effects of surface- and deep-level diversity on group cohesion. Academy of Management Journal, 41: 96-107.

Harrison, D. A., \& Klein, K. J. 2007. What's the difference? Diversity constructs as separation, variety, or disparity in organizations. Academy of Management Review, 32: 1199-1228.

Hausknecht, J. P., Trevor, C. O., \& Howard, M. J. 2009. Unit-level voluntary turnover rates and customer service quality: Implications of group cohesiveness, newcomer concentration, and size. Journal of Applied Psychology, 94: 1068-1075.

Hegarty, W. H., \& Dalton, D. R. 1995. Development and psychometric properties of the organizational diversity inventory (ODI). Educational Psychological Measurement, 55: 1047-1051.

Herring, C. 2009. Does diversity pay? Race, gender, and the business case for diversity. American Sociological Review, 74: 208-224.

Hewlin, P. F. 2003. And the award for best actor goes to . . . F Facades of conformity in organizational settings. Academy of Management Review, 28: 633-642.
Hewlin, P. F. 2009. Wearing the cloak: Antecedents and consequences of creating facades of conformity. Journal of Applied Psychology, 94: 727-741.

Hicks-Clarke, D., \& Iles, P. 2000. Climate for diversity and its effects on career and organizational attitudes and perceptions. Personnel Review, 29: 324-346.

Hinkin, T. R. 1998. A brief tutorial on the development of measures for use in survey questionnaires. Organizational Research Methods, 1: 104-121.

Hochschild, A. R. 1983. The managed heart. Berkeley: University of California Press.

Hogg, M. A., \& Terry, D. J. 2000. Social identity and selfcategorization processes in organizational contexts. Academy of Management Review, 25: 121-140.

Holvino, E. H., Ferdman, B. M., \& Merrill-Sands, D. 2004. Creating and sustaining diversity and inclusion in organizations: Strategies and approaches. In M. S. Stockdale \& F. J. Cosby (Eds.), The psychology and management of workplace diversity: 245-276. Malden, MA: Blackwell.

Huselid, M. A. 1995. The impact of human resource management practices on turnover, productivity, and corporate financial performance. Academy of Management Journal, 38: 635-672.

Jackson, S. E., Joshi, A., \& Erhardt, N. L. 2003. Recent research on team and organizational diversity: SWOT analysis and implications. Journal of Management, 29: 801-830.

Jasso, G. 2001. Studying status: An integrated framework. American Sociological Review, 66: 96-124.

Jehn, K. A. 1994. Enhancing effectiveness: An investigation of advantages and disadvantages of value-based intra group conflict. International Journal of Conflict Management, 5: 223-238.

Jehn, K. A. 1995. A multimethod examination of the benefits and detriments of intragroup conflict. Administrative Science Quarterly, 40: 256-282.

Jehn, K. A., Chadwick, C., \& Thatcher, S. M. B. 1997. To agree or not to agree: The effects of value congruence, individual demographic dissimilarity, and conflict on workgroup outcomes. International Journal of Conflict Management, 8: 287-305.

Jehn, K. A., \& Mannix, E. A. 2001. The dynamic nature of conflict: A longitudinal study of intragroup conflict and group performance. Academy of Management Journal, 44: 238-251.

Jehn, K. A., Northcraft, G. B., \& Neale, M. A. 1999. Why differences make a difference: A field study of diversity, conflict, and performance in workgroups. Administrative Science Quarterly, 44: 741-763.

Kacmar, K. M., Andrews, M. C., Van Rooy, D. L., Steilberg, R. C., \& Cerrone, S. 2006. Sure everyone can be 
replaced. . . but at what cost? Turnover as a predictor of unit-level performance. Academy of Management Journal, 49: 133-144.

Kahn, W. A. 1990. Psychological conditions of personal engagement and disengagement at work. Academy of Management Journal, 33: 692-724.

King, E., Hebl, M., \& Beal, D. 2009. Conflict and cooperation in diverse workgroups. Journal of Social Issues, 65: 261-285.

Knottnerus, J. D. 1997. The theory of structural ritualization. Advances in Group Processes, 14: 257-279.

Kossek, E. E., \& Zonia, S. C. 1993. Assessing diversity climate: A field study of reactions to employer efforts to promote diversity. Journal of Organizational Behavior, 14: 61-81.

Larkey, L. K. 1996. Toward a theory of communicative interactions in culturally diverse workgroups. Academy of Management Review, 21: 463-491.

Lau, D., \& Murnighan, J. K. 1998. Demographic diversity and faultlines: The compositional dynamics of organizational groups. Academy of Management Review, 23: 325-340.

Lawler, E. E., \& Porter, L. W. 1967. The effect of performance on job satisfaction. Industrial Relations, 7: 20-28.

Lee, T. W., \& Mitchell, T. R. 1994. An alternative approach: The unfolding model of employee turnover. Academy of Management Review, 19: 51-89.

Leonardelli, G. J., \& Toh, S. M. 2011. Perceiving expatriate coworkers as foreigners encourages aid: Social categorization and procedural justice together improve intergroup cooperation and dual identity. Psychological Science, 22: 110-117.

Lovelace, K., Shapiro, D. L., \& Weingart, L. R. 2001. Maximizing cross-functional new product teams' innovativeness and constraint adherence: A conflict communications perspective. Academy of Management Journal, 44: 7779-7793.

MacKinnon, D. P., Lockwood, C. M., Hoffman, J. M., West, S. G., \& Sheets, V. 2002. A comparison of methods to test mediation and other intervening variable effects. Psychological Methods, 7: 83-104.

Mannix, E., \& Neale, M. 2005. What differences make a difference? The promise and reality of diverse teams in organizations. Psychology in the Public Interest, 6(2): 31-55.

Mayer, D. M., Nishii, L. H., Schneider, B., \& Goldstein, H. 2007. The precursors and products of fair climates: The effects of leader personality and self versus other's justice perceptions. Personnel Psychology, 60: 929-963.

McKay, P. R., Avery, D. R., Tonidandel, S., Morris, M. A.,
Hernandez, M., \& Hebl, M. R. 2007. Racial differences in employee retention: Are diversity climate perceptions the key? Personnel Psychology, 60: 35-62.

Milliken, F. M., \& Martins, L. L. 1996. Searching for common threads: Understanding the multiple effects of diversity in organizational groups. Academy of Management Review, 21: 402-433.

Mohammed, S., \& Angell, L. C. 2004. Surface- and deeplevel diversity in workgroups: Examining the moderating effects of team orientation and team process on relationship conflict. Journal of Organizational Behavior, 25: 1015-1039.

Mor Barak, M. E., \& Cherin, D. A. 1998. A tool to expand organizational understanding of workforce diversity: Exploring a measure of inclusion-exclusion. Administration in Social Work, 22(1): 47-63.

Mor Barak, M. E., Cherin, D. A., \& Berkman, S. 1998. Organizational and personal dimensions of Diversity Climate: Ethnic and gender differences in employee diversity perceptions. Journal of Applied Behavioral Sciences, 34: 82-104.

Morrison, E. W., \& Milliken, F. J. 2000. Organizational silence: A barrier to change and development in a pluralistic world. Academy of Management Review, 25: 706-725.

Niehoff, B. P., \& Moorman, R. H. 1993. Justice as a mediator of the relationship between methods of monitoring and organizational citizenship behavior. Academy of Management Journal, 36: 527-556.

Oakes, P. J., Haslam, S. A., \& Turner, J. C. 1994. Stereotyping and social reality. Oxford, UK \& Cambridge, MA: Blackwell.

Ostroff, C. 1992. The relationship between satisfaction, attitudes, and performance: An organizational level analysis. Journal of Applied Psychology, 77: 963974.

Pearsall, M. J., Ellis, A. P. J., \& Evans, J. M. 2008. Unlocking the effects of gender faultlines on team creativity: Is activation the key? Journal of Applied Psychology, 93: 225-234.

Pearson, C. M., Andersson, L. M., \& Porath, C. L. 2000. Assessing and attacking workplace incivility. Organizational Dynamics, 29(2): 123-137.

Pelled, L. H. 1996. Demographic diversity, conflict, and work group outcomes: An intervening process theory. Organization Science, 7: 615-631.

Pelled, L. H., Eisenhardt, K. M., \& Xin, K. R. 1999. Exploring the black box: An analysis of work group diversity, conflict, and performance. Administrative Science Quarterly, 44: 1-28.

Pinkley, R. 1990. Dimensions of conflict frame: Disputant interpretations of conflict. Journal of Applied Psychology, 75: 117-126. 
Pollner, F. 2008. Bias against women in science: It's still there, and it's got to go. The NIH Catalyst, MarchApril. http://www.nih.gov/catalyst/2008/08.03.01/ page1.html.

Polzer, J. T., Milton, L. P., \& Swann, W. B., Jr. 2002. Capitalizing on diversity: Interpersonal congruence in small work groups. Administrative Science Quarterly, 47: 296-324.

Preacher, K. J., Rucker, D. D., \& Hayes, A. F. 2007. Addressing moderated mediation hypotheses: Theory, methods, and prescriptions. Multivariate Behavioral Research, 42: 185-227.

Ragins, B. R. 2008. Disclosure disconnects: Antecedents and consequences of disclosing invisible stigmas across life domains. Academy of Management Review, 33: 194-215.

Rahim, M. A., \& Bonoma, T. V. 1979. Managing organizational conflict: A model for diagnosis and intervention. Psychological Reports, 44: 1323-1344.

Ramarajan, L. 2009. Opening up or shutting down? The effects of multiple identities on problem solving. Harvard Business School working paper series no. 10-041. Boston.

Randel, A. E. 2002. Identity salience: A moderator of the relationship between group gender composition and work group conflict. Journal of Organizational Behavior, 23: 749-766.

Ridgeway, C. L. 1991. The social construction of status value: Gender and other nominal characteristics. Social Forces, 70: 367-386.

Ridgeway, C. L., \& Berger, J. 1986. Expectations, legitimation, and dominance behavior in task groups. American Sociological Review, 51: 603-617.

Ridgeway, C. L., \& Correll, S. J. 2006. Consensus and the creation of status beliefs. Social Forces, 85: 431-453.

Roberson, Q. M. 2006. Disentangling the meanings of diversity and inclusion in organizations. Group and Organization Management, 31: 212-236.

Rothbard, N. P., \& Ramarajan, L. 2009. Checking your identities at the door? Positive relationships between nonwork and work identities. In L. M. Roberts \& J. E. Dutton (Eds.), Exploring positive identities and organizations: Building a theoretical and research foundation: 125-148. New York: Routledge.

Satorra, A. 2000. Scaled and adjusted restricted tests in multi-sample analysis of moment structures. In R. D. H. Heijmans, D. S. G. Pollock \& A. Satorra (Eds.), Innovations in multivariate statistical analysis: A Festschrift for Heinz Neudecker: 233-247. London: Kluwer Academic.

Schwab, D. P. 1980. Construct validity in organizational behavior. In B. M. Staw \& L. L. Cummings (Eds.),
Research in organizational behavior, vol. 2: 3-43. Greenwich, CT: JAI.

Shore, L. M., Randel, A. E., Chung, B. G., Dean, M. A., Ehrhart, K. H., \& Singh, G. 2011. Inclusion and diversity in work groups: A review and model for future research. Journal of Management, 37: 1262-1289.

Sidanius, J., \& Pratto, F. 1999. Social dominance: An intergroup theory of social hierarchy and oppression. Cambridge, UK: Cambridge University Press.

Simons, T. L., \& Peterson, R. S. 2000. Task conflict and relationship conflict in top management teams: The pivotal role of intragroup trust. Journal of Applied Psychology, 85: 102-111.

Tajfel, H., \& Turner, J. C. 1986. The social identity theory of intergroup behavior. In S. Worchel \& W. Austin (Eds.), Psychology of Intergroup Relations: 7-24. Chicago: Nelson Hall.

U.S. Department of Labor Center for Faith-Based Community Initiatives. 2008. Cost-of-turnover worksheet. http://www.dol.gov/cfbci/turnover.htm. Accessed July 5.

U.S. Equal Employment Opportunity Commission. 2008. Job bias charges rise $9 \%$ in 2007, EEOC reports. http://www.eeoc.gov/press/3-5-08.html.

van Knippenberg, D., De Dreu, C. K. W., \& Homan, A. C. 2004. Work group diversity and group performance: An integrative model and research agenda. Journal of Applied Psychology, 89: 1008-1022.

van Knippenberg, D., \& Schippers, M. C. 2007. Work group diversity. In M. I. Posner \& M. K. Rothbard (Eds.), Annual review of psychology, vol. 58: 515541. Palo Alto, CA: Annual Reviews.

Vandenberg, R. J., \& Nelson, J. B. 1999. Disaggregating the motives underlying turnover intentions: When do intentions predict turnover behavior? Human Relations, 52: 1313-1336.

Wagner, D. G., Ford, R. S., \& Ford, T. W. 1986. Can gender inequalities be reduced? American Sociological Review, 51: 47-61.

Wanous, J. P., Reichers, A. E., \& Hudy, M. J. 1997. Overall job satisfaction: How good are single-item measures? Journal of Applied Psychology, 82: 247-52.

Webber, S. S., \& Donahue, L. M. 2001. Impact of highly and less job-related diversity on work group cohesion and performance: A meta-analysis. Journal of Management, 27: 141-162.

Wegge, J., Roth, C., Neubach, B., Schmidt, K. H., \& Kanfer, R. 2008. Age and gender diversity as determinants of performance and health in a public organization: The role of task complexity and group size. Journal of Applied Psychology, 93: 1301-1313.

Williams, K. Y., \& O’Reilly, C. A. 1998. Demography and 
diversity in organizations: A review of 40 years of research. In B. M. Staw \& L. L. Cummings (Eds.), Research in organizational behavior, vol. 20: 77140. Greenwich, CT: JAI.

Yoder, J. D. 1994. Looking beyond numbers: The effects of gender status, job prestige, and occupational gender-typing on tokenism processes. Social Psychology Quarterly, 57: 150-159.

Zohar, D. 2000. A group-level model of safety climate: Testing the effect of group climate on microaccidents in manufacturing jobs. Journal of Applied Psychology, 85: 587-596.

Zohar, D. 2002. Modifying supervisory practices to im- prove subunit safety: A leadership-based intervention model. Journal of Applied Psychology, 87: 156-163.

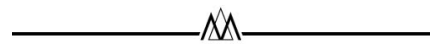

Lisa H. Nishii (lhn5@cornell.edu) is an associate professor of human resource studies at the ILR School at Cornell University. She received her Ph.D. from the University of Maryland. Her research interests include diversity and inclusion, climate, employees' subjective perceptions of HR practices, and national culture.

SA 